\title{
Epidemiological Features of Ischemic Brain Stroke; a Cross-Sectional Hospital-Based Study
}

\author{
Anita Sabzghabaei ${ }^{1}$, Sohrab Aeinechian ${ }^{1}$, Majid Shojaee ${ }^{1}$, Parvin Kashani ${ }^{1}$ and Mohammad \\ Manouchehrifar, ${ }^{1, *}$ \\ ${ }^{1}$ Department of Emergency Medicine, Shahid Beheshti Medical University, Tehran, Iran \\ "Corresponding author: Department of Emergency Medicine, Loghman Hakim Hospital, Tehran, Iran. Tel: +98-9129247258, Email: arash_manouchehrifar@yahoo.com
}

Received 2018 May 06; Revised 2018 December 06; Accepted 2018 December 19.

\begin{abstract}
Background: Assessing the prevalence of brain stroke and its clinical patterns across countries and nations could be valuable. It is an important concern for Iran as one of the countries with a high rate of stroke.

Objectives: The present study was aimed to assess the epidemiological aspects of ischemic brain stroke.

Methods: This cross-sectional study was conducted in Loghman-e-Hakim Hospital, Tehran, Iran from January 2013 to December 2016. The data were gathered by retrospectively reviewing the hospital records.

Results: In this study, 2041 cases were admitted that 1145 (56\%) cases were male. The mean age of the patients was $66.50 \pm 13.49$ years. The most common underlying risk factor was hypertension in $73.7 \%$ followed by diabetes mellitus in $44.3 \%$. Left carotid stenosis was reported in $17.2 \%$ of the cases and right carotid stenosis in $9.5 \%$. Left ventricular ejection fraction $<40 \%$ was found in $8.6 \%$ of the cases. The most common areas involved in the brain CT scanning were periventricular areas in $20.5 \%$, left middle cerebral artery in $15.4 \%$, and lacunar infarction $8.8 \%$ of the cases. In addition, 214 patients died indicating a crude mortality rate of $10.5 \%$.

Conclusions: The prevalence of ischemic brain stroke in males is slightly higher than females and the mean age of the patients was estimated to be 66 years. The most common risk factors are comprised of hypertension, diabetes mellitus, and smoking. Carotid stenosis is evident in more than $25 \%$ of the patients, and the mortality rate was $10 \%$ in the studied population.
\end{abstract}

Keywords: Epidemiology, Iran, Risk Factors, Stroke

\section{Background}

Stroke is the third most common cause of death in developed countries and the most common neurological disease all over the world. The annual incidence of stroke has been estimated to be about 15 million cases that onethird die and one-third suffer from a permanent disability. In total, more than $80 \%$ of all stroke-induced deaths in the world occur in developing countries (1-8). Previous studies have shown that the risk of stroke is doubled after the age of 55. It should be also mentioned that developed and developing countries are rapidly moving towards becoming older due to increased community hygiene that requires extensive health care for their elderly population (9-13). Risk factors related to cerebrovascular thrombotic events, such as ischemic stroke, consist of hypertension and diabetes with different patterns in each community based on different cultural characteristics and some other effective factors (14-16). Thus assessing the prevalence of ischemic brain stroke and its clinical patterns is an impor- tant concern for Iran as one of the countries with the high rate of ischemic brain stroke.

\section{Objectives}

The present study was aimed to assess the epidemiological aspects of the ischemic brain stroke in one of the main referral hospitals for stroke patients in Tehran, Iran.

\section{Methods}

\subsection{Study Design}

This cross-sectional study was conducted in Loghmane-Hakim Hospital, Tehran, Iran from January 2013 to December 2016. This hospital is one of the main educational hospitals in Tehran affiliated to Shahid Beheshti Medical University (SBMU). Total monthly patients refer to this hospital is approximately 10000 that almost 3000 of them are admitted to the wards. Method of the study was approved 
by the Ethics Committee of SBMU with the ethic number of IR.SBMU.MSP.REC.1395.225. The information on this study was kept confidential and secured.

\subsection{Study Population}

All eligible patients older than 18 years with the final diagnosis of ischemic brain stroke were admitted during the study period. Those with other co-existing non-acute neurological diseases or history of traumatic brain injuries were excluded.

\subsection{Data Gathering}

The process of data gathering was performed by retrospectively reviewing the hospital records to collect baseline demographic characteristics, risk factors, patients' chief complaint and clinical manifestations, oral medications, laboratory parameters, as well as the findings of imaging assessments, including carotid Doppler ultrasound and computed tomography (CT) scans or brain magnetic resonance imaging (MRI). Also, the in-hospital mortality rate was also assessed.

\subsection{Statistical Analysis}

The results were presented as mean \pm standard deviation (SD) for quantitative variables and were summarized by absolute frequencies and percentages for categorical variables. The normality of data was analyzed using the Kolmogorov-Smirnoff test. Categorical variables were compared using chi-square test or Fisher's exact test when more than $20 \%$ of cells with an expected count of less than 5 were observed. For the statistical analysis, the statistical software SPSS version 16.0 (SPSS Inc., Chicago, IL) was used. The $P$ value of 0.05 or less was considered statistically significant.

\section{Results}

Totally, 2041 cases with the mean age of $66.50 \pm 13.49$ years were studied that 1145 cases were male (56\%) and 896 (44\%) were female. The mean age of the patients was 65.17 \pm 13.66 years in males and $68.18 \pm 13.10$ years in females indicating a statistically significant difference between the two genders $(\mathrm{P}<0.001)$.

\subsection{Baseline Characteristics}

Details of the patients' baseline characteristics were summarized in Table 1. Although the most number of the cases were admitted during the year of 2015, no significant difference was observed compared with the other years ( $\mathrm{P}$ $>0.05$ ). With respect to laboratory parameters, lipid profile abnormality was the most frequent finding. According to the prescribed medication (drug history), insulin was administered in $39.4 \%$ and aspirin in $39.1 \%$ of the cases. The most common underlying risk factor was hypertension in 73.7\% followed by diabetes mellitus in $44.3 \%$ and smoking in $36.6 \%$ of the cases. Raised systolic blood pressure $(>140$ $\mathrm{mmHg}$ ) and diastolic blood pressure $(>90 \mathrm{mmHg}$ ) was reported in $53.6 \%$ and $28.0 \%$ of the cases, respectively. The mean left ventricular ejection fraction in echocardiography was $53.2 \pm 9.5 \%$; however, lower than $40 \%$ was observed only in $8.6 \%$ of the cases.

\subsection{Stroke Characteristics}

Details of ischemic brain stroke characteristics in the studied patients were summarized in Table 2. The 3 most chief complaints of the patients were weakness (39.3\%), paresis (28.3\%), and paresthesia (23.2\%). In terms of the physical exam, hemiparesis was reported in $60.9 \%$ of the cases which was more frequent than the other parameters. Naturally, a significant number of the patients simultaneously had multiple signs or symptoms.

Details of the involved area on brain imaging related to the studied patients were reported in Table 3. With respect to the brain imaging, whether CT scan or MRI, the most common areas involved in the brain were periventricular areas in $20.5 \%$, left middle cerebral artery (MCA) territory in $15.4 \%$, lacunar in $8.8 \%$, and pons in $7.1 \%$ of the cases. Totally, among 851 cases that underwent carotid Doppler ultrasound assessment, left carotid stenosis was revealed in $17.15 \%$ and right carotid stenosis in $9.51 \%$ of the cases.

Intravenous thrombolytic was administered in just 94 patients that led to the improvement in 82 cases (87.2\%), but led to intracranial hemorrhage (ICH) in other 12 cases (12.8\%). In addition, 214 patients died during in-hospital follow-up, indicating a crude mortality rate of $10.5 \%$. The involvement of pons was found in $45.3 \%$, right hemisphere in $5.6 \%$, left hemisphere in $14.0 \%$, lacunar in $15.4 \%$, left MCA in $15.9 \%$, right occiput in $1.4 \%$, and left occiput in $2.3 \%$ of these cases.

\section{Discussion}

The results of this study indicated that first, the trend of ischemic brain stroke has not significantly changed in recent years in the studied hospital. Second, the frequency of ischemic brain stroke distribution was slightly higher in males than females, but the incidence rate of females is far higher than males. Concerning risk factors associated with ischemic brain stroke, the most common risk factor such as hypertension was observed in about $74 \%$ of the patients, followed by other common risk factors, including diabetes mellitus in $44 \%$ and smoking in $36.6 \%$. In terms of laboratory findings, lipid profile impairment was also associated 


\begin{tabular}{|c|c|}
\hline Variable & No. (\%) \\
\hline \multicolumn{2}{|l|}{ Gender } \\
\hline Male & $1145(56.1)$ \\
\hline Female & $896(43.9)$ \\
\hline \multicolumn{2}{|l|}{ Year of hospital admission } \\
\hline 2013 & $508(24.9)$ \\
\hline 2014 & $471(23.1)$ \\
\hline 2015 & $701(34.3)$ \\
\hline 2016 & $361(17.7)$ \\
\hline \multicolumn{2}{|l|}{ Underlying risk factor } \\
\hline Hypertension & $1504(73.7)$ \\
\hline Diabetes mellitus & $904(44.3)$ \\
\hline Smoking & $747(36.6)$ \\
\hline Ischemic heart disease & $653(32.0)$ \\
\hline Hyperlipidemia & $632(31.0)$ \\
\hline Previous cerebrovascular accident & $581(28.5)$ \\
\hline Opium abuse & $212(10.4)$ \\
\hline Alcohol consumption & $212(10.4)$ \\
\hline Dysrhythmia & $81(4.0)$ \\
\hline Renal failure & $59(2.9)$ \\
\hline Fatty liver & $40(2.0)$ \\
\hline \multicolumn{2}{|l|}{ Drug history } \\
\hline Insulin & $804(39.4)$ \\
\hline Aspirin & $798(39.1)$ \\
\hline Warfarin & $118(5.8)$ \\
\hline ОСР & $2(0.1)$ \\
\hline \multicolumn{2}{|l|}{ Abnormal laboratory parameters } \\
\hline Reduced HDL level $(<40 \mathrm{mg} / \mathrm{dL})$ & $1336(65.5)$ \\
\hline Raised LDL level (> $100 \mathrm{mg} / \mathrm{dL})$ & $1026(50.3)$ \\
\hline Increased total cholesterol level (> $200 \mathrm{mg} / \mathrm{dL}$ ) & $489(24.0)$ \\
\hline Increased triglyceride level (> $200 \mathrm{mg} / \mathrm{dL}$ ) & $412(20.2)$ \\
\hline Hyperglycemia (blood sugar > $200 \mathrm{mg} / \mathrm{dL}$ ) & $387(19.0)$ \\
\hline Raised creatinine level (> $1.5 \mathrm{mg} / \mathrm{dL}$ ) & $259(12.7)$ \\
\hline
\end{tabular}

Abbreviations: HDL, high-density lipoprotein; LDL, low-density lipoprotein $\mathrm{OCP}$, oral contraceptive pill.

with increased low-density lipoprotein (LDL) and reduced high-density lipoprotein (HDL) in these patients. However, left ventricular dysfunction was only apparent in $8.6 \%$ of the patients. Also, in carotid Doppler evaluation, left and right carotid stenosis was seen in $15.8 \%$ and $8.8 \%$, respectively. Given the results of the present study on the distribution of sex and age of ischemic brain stroke in compar-

\begin{tabular}{ll}
\hline Table 2. Details of the Stroke Characteristics in the Studied Patients $(\mathrm{N}=2041)$ \\
\hline Variable & No. $(\%)$ \\
\hline Chief complaint & \\
\hline Weakness & $802(39.3)$ \\
\hline Paresis & $577(28.3)$ \\
\hline Paresthesia & $473(23.2)$ \\
\hline Resolved focal neurologic deficit & $40(1.9)$ \\
\hline Seizure & $32(1.6)$ \\
\hline Others & $117(5.7)$ \\
\hline Clinical sign & \\
\hline Dysarthria & $959(47.0)$ \\
\hline Right hemiparesis & $812(39.8)$ \\
\hline Left hemiparesis & $430(21.1)$ \\
\hline Lower extremity weakness & $398(19.5)$ \\
\hline Upper extremity weakness & $379(18.6)$ \\
\hline Visual impairment & $204(10.0)$ \\
\hline Dysphagia & $108(5.3)$ \\
\hline
\end{tabular}

ison to the other studies in Iran, we conclude that the occurrence of ischemic brain stroke in Iran in all age groups is slightly higher in females than males in most studies (about 51 to $53 \%$ in females) $(17,18)$, which is slightly contradictory with our study. However, stroke has been higher in young men, especially between the ages of 15 and 45 (19). In our study, the prevalence of stroke was higher in males than females in only 131 cases aged less than 45 years, which is consistent with previous studies. Therefore, it can be concluded that the occurrence of ischemic stroke is most commonly seen in men than women in lower ages, while over the age of 45 years, the results vary in different studies.

In the current study, the mean age of ischemic brain stroke was estimated to be 66.5 years. In general, the mean age of stroke in Iran was in the seventh decade of life (20). In a study by Talebi et al. in 2014, the mean age of the patients was 68.9 (21), which was close to our study. In a study by Shaafi et al. in $2014,71 \%$ of the patients were male and 28.9\% were female, which was similar to our study, indicating a higher distribution of stroke in males than females (9). In a study by Borhani-Haghighi et al. in 2013, 53.6\% of the patients were male and $46.4 \%$ were female, suggesting a higher prevalence of stroke in males than females (13). In the study by Fahimfar et al. in 2017, 1089 males and 1289 females were under follow-up. During the follow-up of 9.3 years, 69 ischemic strokes occurred with an incidence of 4.5 and 2.5 in males and females, respectively (22).

Concerning the risk factors associated with ischemic 


\begin{tabular}{|c|c|}
\hline Involved Brain Region & No. $(\%)$ \\
\hline Right frontal & $51(2.5)$ \\
\hline Left frontal & $30(1.5)$ \\
\hline Right frontotemporal & $12(0.5)$ \\
\hline Left frontotemporal & $18(0.9)$ \\
\hline Right temporal & $35(1.7)$ \\
\hline Left temporal & $31(1.5)$ \\
\hline Right temporoparietal & $12(0.6)$ \\
\hline Left temporoparietal & $6(0.3)$ \\
\hline Right parietal & $38(1.9)$ \\
\hline Left parietal & $25(1.2)$ \\
\hline Right cerebellum & $48(2.3)$ \\
\hline Left cerebellum & $28(0.6)$ \\
\hline Periventricular & $418(20.5)$ \\
\hline Right occiput & $41(2.0)$ \\
\hline Left occiput & $22(1.0)$ \\
\hline Right sylvian fissure & $12(0.6)$ \\
\hline Left sylvian fissure & $8(0.4)$ \\
\hline Right hemisphere & $12(0.6)$ \\
\hline Left hemisphere & $32(1.6)$ \\
\hline Right internal capsule & $35(1.7)$ \\
\hline Left internal capsule & $33(1.6)$ \\
\hline Gseneralized atrophy & $57(2.8)$ \\
\hline Right thalamus & $45(2.2)$ \\
\hline Left thalamus & $31(1.5)$ \\
\hline Pons & $145(7.1)$ \\
\hline Corona radiata & $12(0.6)$ \\
\hline Lacunar & $181(8.8)$ \\
\hline Left ACA territory & $30(1.5)$ \\
\hline Right MCA territory & $71(3.4)$ \\
\hline Left MCA territory & $315(15.4)$ \\
\hline Right PCA territory & $48(2.3)$ \\
\hline Left PCA territory & $64(3.1)$ \\
\hline Right carotid territory & $12(0.6)$ \\
\hline Left carotid territory & $32(1.6)$ \\
\hline
\end{tabular}

stroke in Iran, almost all of our study results are consistent with previous studies, in which hypertension was a predominant risk factor in most studies. Diabetes and cigarette smoking have also been considered prevalent risk factors in other studies. In a systematic review car- ried out by Hosseini et al. in 2010 on the studies conducted in Iran, in terms of the distribution of risk factors associated with stroke, hypertension is the most common risk factor for stroke. Cardiovascular disease (54\%), especially rheumatic heart disease (34\%), was the most common cause of death in stroke in young people (23). In subjects over $35,20 \%$ of the patients with ischemic stroke had a heart origin for embolism, especially rheumatoid mitral stenosis (19). In the study of Talebi et al. in 2014, high blood pressure was reported in $72.3 \%$ of females and $59.3 \%$ in males, while $28.8 \%$ of females and $18.7 \%$ of males had diabetes and smoking was reported in $6.3 \%$ of females and $35.3 \%$ in males (21), which indicated a high prevalence of hypertension along with other risk factors for ischemic stroke. In the study of Sarrafzadegan et al. in 2017, the prevalence of hypertension and hyperglycemia in the stroke group was significantly higher than in the control group (24). In the study by Fahimfar et al. in 2017, among risk factors for stroke, including age over 65 , male sex, hypertension, diabetes, and chronic kidney disease (22) three risk factors, including hypertension, diabetes mellitus, and smoking were considered to be major risk factors for ischemic stroke.

As a result of our study, about a quarter of the patients underwent carotid Doppler ultrasound, which one-sided carotid artery stenosis was observed in a small number of the patients. The frequency of carotid stenosis associated with ischemic stroke has been very different in various studies. In the study by Chang et al. in 2002, the prevalence of carotid stenosis was $24.3 \%$ (25), in Tan et al. study in Taiwan in 2005, it was 6\% (26), and in Fernandes et al. study in 2016 in India was 24\% (27). Overall, the incidence of carotid artery stenosis in patients with ischemic stroke appears to be visible in $6 \%$ to $24 \%$ of the patients and therefore, this finding in these patients will not predominate in the vast majority of the patients.

Finally, the rate of mortality due to ischemic stroke was $10.5 \%$ in our study. The 28 -day mortality rate for stroke in Iranian studies is estimated to be between $19.2 \%$ and $31.5 \%$, which was lower in our study than in other studies. However, a wide range of deaths from stroke is provided in many countries. The mortality rate pointed in African areas was 30\% (28), in China ranged from $27.2 \%$ to $32.9 \%$ (29), in Latin countries ranged from $19.3 \%$ to $26.2 \%$ (30), and in India ranged from $24.5 \%$ to $37.1 \%$ (31). This figure equals (17\%) in Japan and equals $22 \%$ in most developing countries (32). It seems that mortality rates are predominantly influenced by several factors such as the severity and pattern of inter-cerebral involvement, the presence of uncontrolled risk factors, the lifestyle of the patients, their dominant diet, and even genetic factors. 


\subsection{Limitations}

This study was conducted as a single-center survey and could not reflect the epidemiological aspects of stroke in the whole Iranian society. Furthermore, short-term and long-term outcomes of the patients and also in-patient and out-patient therapies would be so important data in such epidemiological studies.

\subsection{Conclusions}

In the final conclusion, according to our study on patients with ischemic brain stroke in selected Iranian society, the prevalence of ischemic stroke in males is slightly higher than females and the mean age of the patients was estimated to be 66 years. The most common risk factors are comprised of hypertension, diabetes mellitus, and smoking. Carotid stenosis is evident in more than $25 \%$ of the patients, and the mortality rate was 10\% in the studied population.

\section{Footnotes}

Conflict of Interests: The authors declare that they have no conflict of interest.

Ethical Approval: Method of the study was approved by the Ethics Committee of SBMU with the ethic number of IR.SBMU.MSP.REC.1395.225. The information on this study was kept confidential and secured.

Funding/Support: The authors declare that they have no funding support.

\section{References}

1. Goldstein LB, Adams R, Becker K, Furberg CD, Gorelick PB, Hademenos G, et al. Primary prevention of ischemic stroke: A statement for healthcare professionals from the Stroke Council of the American Heart Association. Stroke. 2001;32(1):280-99. doi: 10.1161/01.STR.32.1.280. [PubMed: 11136952].

2. Roth EJ, Lovell L, Harvey RL, Heinemann AW, Semik P, Diaz S. Incidence of and risk factors for medical complications during stroke rehabilitation. Stroke. 2001;32(2):523-9. doi: 10.1161/01.STR.32.2.523. [PubMed: 11157192].

3. Delavar Kasmaei H, Baratloo A, Nasiri Z, Soleymani M, Oraee Yazdani M. Recombinant tissue plasminogen activator administration in patients with cerebrovascular accident; a case series. Arch Neurosci. 2015;2(3). e23315. doi: 10.5812/archneurosci.23315.

4. Taheraghdam AA, Sharifipour E, Pashapour A, Namdar S, Hatami A, Houshmandzad S, et al. Allopurinol as a preventive contrivance after acute ischemic stroke in patients with a high level of serum uric acid: A randomized, controlled trial. Med Princ Pract. 2014;23(2):1349. doi: 10.1159/000355621. [PubMed: 24296871]. [PubMed Central: PMC5586842].

5. Baratloo A, Rahimpour L, Abushouk AI, Safari S, Lee CW, Abdalvand A. Effects of telestroke on thrombolysis times and outcomes: A meta-analysis. Prehosp Emerg Care. 2018;22(4):472-84. doi: 10.1080/10903127.2017.1408728. [PubMed: 29345529].
6. Kapral MK, Fang J, Hill MD, Silver F, Richards J, Jaigobin C, et al. Sex differences in stroke care and outcomes: Results from the Registry of the Canadian Stroke Network. Stroke. 2005;36(4):809-14. doi: 10.1161/01.STR.0000157662.09551.e5. [PubMed:15731476].

7. Baratloo A, Forouzanfar MM, Hashemi B, Safari S, Delavar Kasmaei H, Rouhipour A, et al. Tissue plasminogen activator: A literature review. Arch Neurosci. 2016;3(1). e30452. doi: 10.5812/archneurosci.30452.

8. Manouchehrifar M, Lakestani M, Kashani P, Safari S. Sonographic diameter of optic nerve sheath in differentiation of ischemic and hemorrhagic strokes; a diagnostic accuracy study. Am J Emerg Med. 2018;36(11):2064-7. doi: 10.1016/j.ajem.2018.08.041. [PubMed: 30135026].

9. Shaafi S, Sharifipour E, Rahmanifar R, Hejazi S, Andalib S, Nikanfar M, et al. Interleukin-6, a reliable prognostic factor for ischemic stroke. Iran J Neurol. 2014;13(2):70-6. [PubMed: 25295149]. [PubMed Central: PMC4187333].

10. Mangum SA, Kraenow KR, Narducci WA. Identifying at-risk patients through community pharmacy-based hypertension and stroke prevention screening projects. J Am Pharm Assoc (Wash). 2003;43(1):50-5. doi: 10.1331/10865800360467042. [PubMed: 23945804].

11. Holroyd-Leduc JM, Kapral MK, Austin PC, Tu JV. Sex differences and similarities in the management and outcome of stroke patients. Stroke. 2000;31(8):1833-7. doi: 10.1161/01.STR.31.8.1833. [PubMed: 10926943].

12. Glader EL, Stegmayr B, Norrving B, Terent A, Hulter-Asberg K, Wester PO, et al. Sex differences in management and outcome after stroke: A Swedish national perspective. Stroke. 2003;34(8):1970-5. doi: 10.1161/01.STR.0000083534.81284.C5. [PubMed: 12855818].

13. Borhani-Haghighi A, Safari R, Heydari ST, Soleimani F, Sharifian M, Yektaparast Kashkuli S, et al. Hospital mortality associated with stroke in southern Iran. Iran J Med Sci. 2013;38(4):314-20. [PubMed: 24293785]. [PubMed Central: PMC3838983].

14. Baratloo A, Safari S, Rouhipour A, Hashemi B, Rahmati F, Motamedi $\mathrm{M}$, et al. The risk of venous thromboembolism with different generation of oral contraceptives; a systematic review and meta-analysis. Emerg (Tehran). 2014;2(1):1-11. [PubMed: 26495334]. [PubMed Central: PMC4614624].

15. Delavar Kasmaei H, Baratloo A, Nasiri Z, Soleymani M, Shirafkan A, Hamedi ZS. Report of nineteen cerebral vein thrombosis referrals to an emergency departmenta case series and literature review. Arch Neurosci. 2014;2(3). e20552. doi:10.5812/archneurosci.20552.

16. Ashrafi F, Baratloo A, Nasiri Z, Soleymani M, Asaadi S. Secondary stroke after thrombolytic administration; a case report. Arch Neurosci. 2014;2(2). e17315. doi: 10.5812/archneurosci.17315.

17. Ahangar AA, Ashraf Vaghefi SB, Ramaezani M. Epidemiological evaluation of stroke in Babol, northern Iran (2001-2003). Eur Neurol. 2005;54(2):93-7. doi: 10.1159/000088643. [PubMed: 16195668].

18. Oveisgharan S, Sarrafzadegan N, Shirani S, Hosseini S, Hasanzadeh P, Khosravi A. Stroke in Isfahan, Iran: Hospital admission and 28-day case fatality rate. Cerebrovasc Dis. 2007;24(6):495-9. doi: 10.1159/000110418. [PubMed: 17971627].

19. Ghandehari K, Moud ZI. Incidence and etiology of ischemic stroke in Persian young adults. Acta Neurol Scand. 2006;113(2):121-4. doi: 10.1111/j.1600-0404.2005.00515.x. [PubMed:16411973].

20. Sarsarshahi A, Boostani R, Sarsarshahi S, Kiani R. Evaluation of risk factors of patients with subarachnoid hemorrhage in Motahari Hospital of Urmia University (March 2002-March 2006). Med J Mashhad Univ Med Sci. 2007;50(4):367-70.

21. Talebi M, Ghertasi M, Taheraghdam A, Andalib S, Sharifipour E. A comparison of risk factors and severity of ischemic stroke in female and male genders in North-West Iran: A cross-sectional study. Iran J Neurol. 2014;13(4):215-9. [PubMed: 25632333]. [PubMed Central: PMC4300796].

22. Fahimfar N, Khalili D, Mohebi R, Azizi F, Hadaegh F. Risk factors for ischemic stroke; results from 9 years of follow-up in a population based cohort of Iran. BMC Neurol. 2012;12:117. doi: 10.1186/1471-2377-12117. [PubMed: 23031547]. [PubMed Central: PMC3517457]. 
23. Ghandehari K, Izadi-Mood Z. Incidence and etiology of pediatric stroke in southern Khorasan. ARYA Atheroscler J. 2010;3(1):29-33.

24. Sarrafzadegan N, Gharipour M, Sadeghi M, Nezafati P, Talaie M, Oveisgharan S, et al. Metabolic syndrome and the risk of ischemic stroke. J Stroke Cerebrovasc Dis. 2017;26(2):286-94. doi: 10.1016/j.jstrokecerebrovasdis.2016.09.019. [PubMed: 27769610].

25. Chang YJ, Ryu SJ, Lin SK. Carotid artery stenosis in ischemic stroke patients with nonvalvular atrial fibrillation. Cerebrovasc Dis. 2002;13(1):16-20. doi:10.1159/000047740. [PubMed: 11810005].

26. Tan TY, Chang KC, Liou CW, Schminke U. Prevalence of carotid artery stenosis in Taiwanese patients with one ischemic stroke. J Clin Ultrasound. 2005;33(1):1-4. doi: 10.1002/jcu.20081. [PubMed: 15690439].

27. Fernandes M, Keerthiraj B, Mahale AR, Kumar A, Dudekula A. Evaluation of carotid arteries in stroke patients using color Doppler sonography: A prospective study conducted in a tertiary care hospital in South India. Int J Appl Basic Med Res. 2016;6(1):38-44. doi: 10.4103/2229516X.174007. [PubMed: 26958521]. [PubMed Central: PMC4765273].
28. Connor MD, Walker R, Modi G, Warlow CP. Burden of stroke in black populations in sub-Saharan Africa. Lancet Neurol. 2007;6(3):269-78. doi: 10.1016/S1474-4422(07)70002-9. [PubMed: 17303533].

29. Liu M, Wu B, Wang WZ, Lee LM, Zhang SH, Kong LZ. Stroke in China: Epidemiology, prevention, and management strategies. Lancet Neurol. 2007;6(5):456-64. doi: 10.1016/S1474-4422(07)70004-2. [PubMed: 17434100].

30. Al-Jishi AA, Mohan PK. Profile of stroke in Bahrain. Neurosciences (Riyadh). 2000;5(1):30-4. [PubMed: 24276659].

31. El Zunni S, Ahmed M, Prakash PS, Hassan KM. Stroke: Incidence and pattern in Benghazi, Libya. Ann Saudi Med.1995;15(4):367-9. doi: 10.5144/0256-4947.1995.367. [PubMed: 17590609].

32. Khosravi A, Rao C, Naghavi M, Taylor R, Jafari N, Lopez AD. Impact of misclassification on measures of cardiovascular disease mortality in the Islamic Republic of Iran: A cross-sectional study. Bull World Health Organ. 2008;86(9):688-96. doi: 10.2471/BLT.07.046532. [PubMed: 18797644]. [PubMed Central: PMC2649498]. 